\title{
Vitamin D Level in Children with Secretory Otitis Media
}

\author{
Yasser M Mandour ${ }^{1}$, Mohammed Shendy², Safaa A Ramadan ${ }^{3}$, Ayman A Mohammady ${ }^{4}$, Samer Badae ${ }^{5}$
}

\begin{abstract}
Background:Vitamin D contains anti-inflammatory properties and plays a function in immune system regulation. Multiple investigations have proven the involvement of vitamin $D$ deficiency in respiratory and middle ear infections.

Aim: The goal of this study was to see how vitamin D levels in the blood affected the development of secretory otitis media (SOM) and adenoid hypertrophy.

Patients and methods: This prospective case-control study included a total of 150 subjects who were divided into two groups; the case group included 100 confirmed cases of SOM and adenoid hypertrophy, and the control group included 50 healthy children. All cases and controls were subjected to complete history taking, thorough ENT examination, and tympanometry. In addition, serum vitamin D was ordered for all subjects. Results: The average age of the study participants was 7.65 years, which was significantly older than the control group (average age, 6.1 ; $p=0.002)$. However, there was no significant gender difference between the two groups $(p=1)$. The commonest season of presentation in the case group was winter (70\%), while the remaining cases presented in summer. The season of the presentation was the difference between the two groups, and it was statistically significant $(p=0.017)$.

Vitamin D levels in the cases were considerably lower (11.82 vs $23.72 \mathrm{ng} / \mathrm{mL}$ in the control group; $p=0.001)$. Using a cutoff value of 18.85 , vitamin D had sensitivity and specificity of 100 and $90 \%$, respectively, with a diagnostic accuracy of $96.7 \%$. All cases showed hypertrophied adenoids on X-ray and type B tympanometry on tympanogram, while all controls showed normal-sized adenoids in addition to type $\mathrm{A}$ tympanogram.

Conclusion: Our findings indicate that low vitamin D levels are associated with exudative SOM and enlarged adenoids. Therefore, in children with these symptoms, measuring serum $25(\mathrm{OH}) \mathrm{D}$ levels should be investigated.

Keywords: Adenoid hypertrophy, Otitis media, Vitamin D.

Otorhinolaryngology Clinics: An International Journal (2021): 10.5005/jp-journals-10003-1366
\end{abstract}

\section{INTRODUCTION}

Vitamin $D$ is thought to help the immune system function more effectively. The creation of defensins, cathelicidin, and other antimicrobial peptides is the suggested mechanism of action.

Furthermore, this vitamin enhances macrophage activity by boosting chemotaxis and phagocytosis. ${ }^{1}$

The link between vitamin D deficiency and infection was first proposed in the context of tuberculosis, but low levels of vitamin $D$ are also linked to a lower level of vacuum infection, while high levels are linked to a higher amount. Furthermore, vitamin D has been linked to inflammatory illnesses, such as autoimmune diseases, allergies, and asthma. ${ }^{2}$

Otitis media $(\mathrm{OM})$ is one of the most prevalent pediatric infections, and it is the most common reason for children under the age of three to seek medical help. Nearly $80 \%$ of children under the age of 7 will be infected at least once, although some will be infected multiple times. ${ }^{3}$

Acute otitis media (AOM), recurrent otitis media, chronic otitis media, and secretory otitis media (SOM), or exudative otitis media (OME) are all types of OM. ${ }^{4}$

Eustachian tube dysfunction is linked to the pathogenesis of OME. $^{5}$

Adenoid hypertrophy, submucosal cleft palate, allergies, upper respiratory tract infections, tumors, sinusitis, $A O M$, and radiation are the most common causes of blockage.

Fluid in the middle ear is caused by obstructing the Eustachian tube. ${ }^{6}$ Many studies have been undertaken in recent years on the risk factors associated with a compromised immune system. Among
${ }^{1}$ Benha Faculty of Medicine, Department of ENT, Benha University, Benha, Egypt

${ }^{2-5}$ Benha Faculty of Medicine, Department of Otorhinolaryngology, Benha University, Benha, Egypt

Corresponding Author: Yasser M Mandour, Benha Faculty of Medicine, Department of ENT, Benha University, Benha, Egypt, Phone: +01009704937, e-mail: ghader_massoud@yahoo.com

How to cite this article: Mandour YM, Shendy M, Ramadan SA, et al. Vitamin D Level in Children with Secretory Otitis Media. Int J Otorhinolaryngol Clin 2021;13(1):18-22.

Source of support: Nil

Conflict of interest: None

them, the importance of vitamin D cannot be overstated. Vitamin D inhibits the production of interleukin and interferon-gamma, which lowers inflammation. ${ }^{7}$

Cayir et al. looked into it. The function of vitamin D in the treatment of children with recurrent otitis suggests that treating vitamin D as well as general treatments is a suitable alternative. ${ }^{8}$

These authors looked at vitamin D levels in children with AOM in another investigation and found that vitamin D insufficiency is linked to the occurrence of middle ear infections. ${ }^{7}$

Vitamin D's function in lowering the risk of recurrent middle ear infections was studied. They advise that children with recurrent AOM have their vitamin D levels checked. Low vitamin D deficiency is common in children with recurrent AOM, and low serum levels are linked to an increased incidence of AOM attacks. ${ }^{9}$

( ) Jaypee Brothers Medical Publishers. 2021 Open Access This article is distributed under the terms of the Creative Commons Attribution 4.0 International License (https://creativecommons.org/licenses/by-nc/4.0/), which permits unrestricted use, distribution, and non-commercial reproduction in any medium, provided you give appropriate credit to the original author(s) and the source, provide a link to the Creative Commons license, and indicate if changes were made. The Creative Commons Public Domain Dedication waiver (http://creativecommons.org/publicdomain/zero/1.0/) applies to the data made available in this article, unless otherwise stated. 
The goal of this study, which took place at Benha University Hospital, was to see how serum vitamin D levels affected the development of SOM and adenoid hypertrophy.

\section{Patients and Methods}

The study is a prospective case-control one designed for patients having SOM and adenoid hypertrophy during the period between July 2019 and December 2019.

The study included a total of 150 subjects. These subjects are subdivided into two groups:

- Case group: 100 cases who were diagnosed with SOM and adenoid hypertrophy.

- Group (B): 50 children with normal adenoid and normal middle ear pressure.

Cases whose ages were between 2 and 12 years from both genders were included in the study. Nevertheless, other ages in addition to cases with normal adenoid or normal middle ear pressure were excluded.

All cases and controls were completely historical and attacked thoroughly. It was also ordered by the X-ray measurement of hollow-neck and the tympaplos and metric. At twenty-five-hour serum level, all of the subjects had their vitamin D levels checked. The clinical pathology laboratory took a $5 \mathrm{~mL}$ blood sample from each patient. The serum levels of $25(\mathrm{OH})$ vitamin $D$ were determined using a display kit and an enzyme-linked immunosorbent assay (ELISA) test technique (ELISA reader, USA).

\section{Ethical Consideration}

An informed written consent from all the parents of the patients and local ethical committee approval were obtained before the onset of this study.

\section{Statistical Analysis}

Data were entered and analyzed using Microsoft Excel software. Then, for the analysis, the data were imported into the social science software's statistical package (SPSS 21.0, IBM/SPSS Inc., Chicago, Illinois). After normality testing with the Kolmogorov-Smirnov and Shapiro-Wilk tests, the baseline characteristics of the study population are reported as frequency and percentage (\%) or mean and standard deviation (SD). For data comparison, Fischer's exact test (FET) is used to compare two sets of independent qualitative data (as a correction for the Chi-square test).

To compare the two sets of parametric and nonparametric quantitative data, the independent sample $t$-test (Student's $t$-test) was utilized.

To evaluate the diagnostic performance of a test or the precision of a test that distinguishes diseased from nondiseased cases, the receiver operating characteristic curve (ROC) analysis was used. The curve's sensitivity and specificity were calculated.

\section{RESULTS}

The study cases were substantially older than the control group (average age, $6.1 ; p=0.002$ ), with an average age of 7.65 years. However, there was no significant gender difference between the two groups $(p=1)$.

Winter is the most typical season for the onset in this group of cases (70\%), with the remainder of instances occurring in summer. The display season differs significantly between the two.

In $n$ terms of vitamin D levels, the case group had significantly lower amounts (11.82 vs 23.72 in controls; $p<0.001)$. All cases showed hypertrophied adenoids on X-ray and type B tympanometry on tympanogram, while all controls showed normal-sized adenoids in addition to type $A$ tympanogram. Table 1 illustrates these data.

On analyzing vitamin D levels in the case group, females had significantly lower vitamin $D$ values compared to males (11.22 vs $12.72 ; p=0.04$ ). Nevertheless, the season of presentation would not have a significant effect on the vitamin D levels. These data are illustrated at Table 2.

On analyzing serum vitamin D levels in controls, neither sex nor season of presentation would have a significant effect on its level $(p>0.05)$. Table 3 illustrates these data.

Using a cutoff value of 18.85 , vitamin D had sensitivity and specificity of 100 and $90 \%$, respectively, with a diagnostic accuracy of $96.7 \%$. Table 4 and Figure 1 illustrate these data.

\section{Discussion}

Children with OM may experience delays in language development and learning difficulties. Serious effects, such as hearing loss, tympanic membrane adhesion or rupture, ear and ossicular issues, and even behavioral disorders, are expected in chronic instances. ${ }^{10}$

Table 1: Comparing cases and controls

\begin{tabular}{|c|c|c|c|c|c|c|}
\hline & \multicolumn{2}{|c|}{$\begin{array}{l}\text { Case with } \\
\text { SOM (100) }\end{array}$} & \multicolumn{2}{|c|}{$\begin{array}{c}\text { Control } \\
\text { group (50) }\end{array}$} & \multirow[b]{2}{*}{ Statistical test } & \multirow[b]{2}{*}{$p$ value } \\
\hline & No. & $\%$ & No. & $\%$ & & \\
\hline Age $($ mean $\pm S D)$ & \multicolumn{2}{|c|}{$7.65 \pm 2.97$} & \multicolumn{2}{|c|}{$6.10 \pm 2.77$} & St $t=3.08$ & $0.002^{* *}$ \\
\hline \multicolumn{7}{|l|}{$\operatorname{Sex}[n(\%)]$} \\
\hline Male & 40 & 40.0 & 20 & 40.0 & \multirow{2}{*}{$\mathrm{FET}=0.0$} & \multirow{2}{*}{1.0} \\
\hline Female & 60 & 60.0 & 30 & 60.0 & & \\
\hline \multicolumn{7}{|l|}{ Season $[n(\%)]$} \\
\hline Summer & 30 & 30.0 & 25 & 50.0 & \multirow{2}{*}{$\mathrm{FET}=5.74$} & \multirow{2}{*}{$0.017^{*}$} \\
\hline Winter & 70 & 70.0 & 25 & 50.0 & & \\
\hline Vitamin $D($ mean $\pm S D)$ & \multicolumn{2}{|c|}{$11.82 \pm 3.58$} & \multicolumn{2}{|c|}{$23.72 \pm 6.03$} & St $t=15.15$ & $<0.001^{* *}$ \\
\hline \multicolumn{7}{|l|}{ X-ray $[n(\%)]$} \\
\hline Hypertrophied & 100 & 100 & 0 & 0.0 & \multirow{2}{*}{$\mathrm{FET}=150.0$} & \multirow{2}{*}{$<0.001^{* *}$} \\
\hline Normal & 0 & 0.0 & 50 & 100 & & \\
\hline \multicolumn{7}{|l|}{ Tympanometry } \\
\hline Bilateral type A & 0 & 0.0 & 50 & 100 & \multirow{2}{*}{$\mathrm{FET}=150.0$} & \multirow{2}{*}{$<0.001^{* *}$} \\
\hline Bilateral type B & 100 & 100 & 0 & 0.0 & & \\
\hline
\end{tabular}


Table 2: Vitamin D levels among case group

\begin{tabular}{|c|c|c|c|c|c|}
\hline \multirow[b]{2}{*}{ Cases with SOM (100) } & \multirow[b]{2}{*}{$N$} & \multicolumn{2}{|c|}{ Vitamin D } & \multirow[b]{2}{*}{ Statistical test } & \multirow[b]{2}{*}{$p$ value } \\
\hline & & Mean & $\pm S D$ & & \\
\hline \multicolumn{6}{|l|}{$\operatorname{Sex}[n(\%)]$} \\
\hline Male & 40 & 12.72 & 3.35 & \multirow{2}{*}{ St $t=2.08$} & \multirow{2}{*}{$0.04^{*}$} \\
\hline Female & 60 & 11.22 & 3.63 & & \\
\hline \multicolumn{6}{|l|}{ Season $[n(\%)]$} \\
\hline Summer & 30 & 11.61 & 3.57 & \multirow{2}{*}{ St $t=0.38$} & \multirow{2}{*}{0.71} \\
\hline Winter & 70 & 11.91 & 3.60 & & \\
\hline
\end{tabular}

Table 3: Vitamin D differences among the control group

\begin{tabular}{|c|c|c|c|c|c|}
\hline \multirow[b]{2}{*}{ Control group (50) } & \multirow[b]{2}{*}{$N$} & \multicolumn{2}{|c|}{ Vitamin D } & \multirow[b]{2}{*}{ Statistical test } & \multirow[b]{2}{*}{$p$ value } \\
\hline & & Mean & $\pm S D$ & & \\
\hline \multicolumn{6}{|l|}{ Sex } \\
\hline Male & 20 & 22.54 & 3.74 & \multirow{2}{*}{ St $t=1.13$} & \multirow{2}{*}{0.26} \\
\hline Female & 30 & 24.51 & 7.11 & & \\
\hline \multicolumn{6}{|l|}{ Season } \\
\hline Summer & 25 & 25.21 & 4.25 & \multirow{2}{*}{ St $t=1.78$} & \multirow{2}{*}{0.081} \\
\hline Winter & 25 & 22.24 & 7.17 & & \\
\hline
\end{tabular}

Table 4: Validity of vitamin $D$ in detection of cases with SOM

\begin{tabular}{llllllll}
\hline & \multicolumn{2}{c}{$\begin{array}{c}\text { Cases with } \\
\text { SOM (20) }\end{array}$} & & \multicolumn{2}{c}{$\begin{array}{c}\text { Control } \\
\text { group (10) }\end{array}$} & & \\
\cline { 2 - 5 } \cline { 6 - 7 } & No. & $\%$ & & No. & $\%$ & Statistical test & p value \\
\hline$\leq 18.85$ & 100 & 100 & 5 & 10.0 & FET $=128.57$ & $<0.001^{* *}$ \\
$>18.85$ & 0 & 0.0 & 45 & 90.0 & & \\
AUC (95\%Cl) & $0.985(0.97-1.0)$ & & & & \\
Cutoff point & 18.85 & & & & & \\
Sensitivity & 100 & & & & & \\
Specificity & 90.0 & & & & & \\
PPV & 95.2 & & & & & \\
NPV & 100 & & & & & \\
Accuracy & 96.7 & & & & & \\
\hline
\end{tabular}

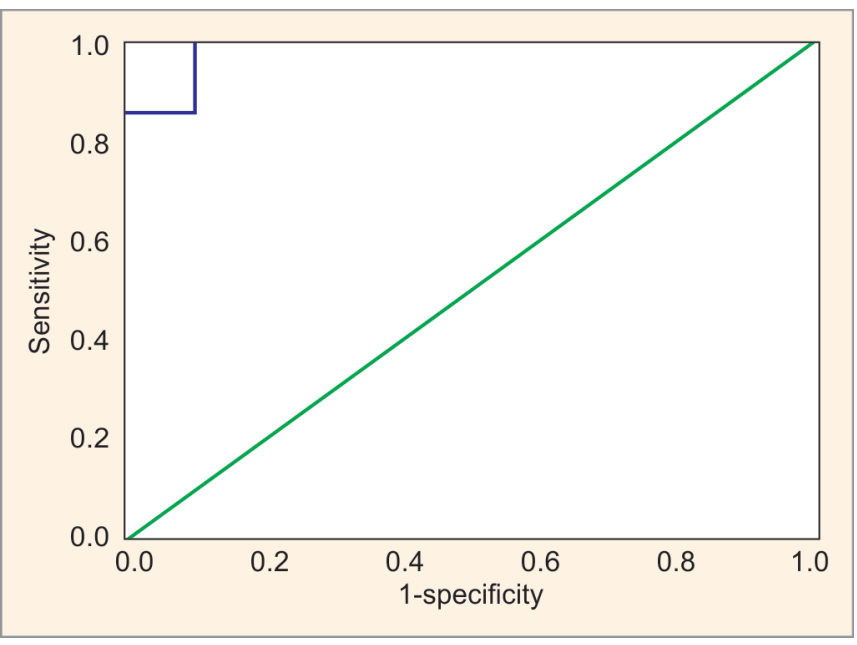

Fig. 1: ROC curve for vitamin D as a predictor for SOM

Vitamin D deficiency is a major health problem around the world, despite of the fact that it plays a crucial role in human health. ${ }^{11}$

Vitamin D contains anti-inflammatory properties and plays a function in immune system regulation. Vitamin D's immunomodulatory action is due to its receptor's effect on the majority of immune cells. ${ }^{12}$

Vitamin D inhibits the function of nuclease factors, interleukins, and interferon-gamma, hence lowering the inflammation. ${ }^{13}$

Vitamin D insufficiency has been linked to respiratory and middle ear infections in the number of studies. ${ }^{7,9}$

Vitamin D levels of more than $30 \mathrm{ng} / \mathrm{mL}$ were found to reduce the incidence of respiratory infections considerably $(p=0.0001) .{ }^{14}$
The purpose of this study was to see how serum vitamin D levels affected the development of SOM and adenoid hypertrophy at Benha University Hospital.

We included a total of 150 subjects who were divided into two groups; the case group included 100 confirmed cases of SOM and adenoid hypertrophy, and the control group included 50 healthy children. In another study using the same perspective, 120 children with and without effusion OM were divided into two groups for the study: A study group (40 people) and a control group (80 people). ${ }^{15}$

In our study, the average age of the included subjects was 7.65 and 6.10 years for the case and control, respectively. In the current study, the age of these cases increased significantly ( $p=0.002)$. In another investigation, the age difference between cases and controls was not significant $(p=0.180)$. Cases and controls had average ages of 5.08 and 7.7 years, respectively. ${ }^{16}$

In contrast, another study found that the age of the control group grew dramatically when compared to the cases. The study group's average age was $5.7 \pm 2.6$ years, while the control group's average age was $7.2 \pm 2.2$ years $(p=0.002) .{ }^{15}$

In this investigation, there was no significant variation in gender distribution between the two groups $(p=1)$. Male made up $40 \%$ of the case group and $40 \%$ of the control group, respectively.

There were no significant gender differences between patients and controls in another study $(p=0.579$ ). Male made up $57.5 \%$ of the cases and $53.7 \%$ of the controls. ${ }^{16}$

During ad stations, there was a significant difference between the two groups $(p=0.017)$. Winter was the most common group of cases $(70 \%)$, but both winter and summer had the same proportion (50\%) than the control. The development of SOM has many hazardous factors, but respective upper infections are the most important of them. Superior neighborhood infections are more common in winter. This accepts our research results. 
Furthermore, the two most important determinants determining serum vitamin $D$ levels are season and race. ${ }^{17}$ The lowest vitamin $D$ concentrations were seen in the winter and autumn. ${ }^{16}$ According to many research, vitamin D levels rise in the summer and fall in the winter due to our reliance on sunlight. ${ }^{18,19}$

In our study, the control group had considerably higher vitamin $D$ levels $(23.72 \mathrm{ng} / \mathrm{mL})$ than the cases $(11.82 \mathrm{ng} / \mathrm{mL} ; p=0.001)$. Vitamin $D$ levels in boys were substantially greater than in girls $(p=0.04)$ in the case group. The sensitivity and specificity of vitamin D are $100 \%$ and $90 \%$, respectively, at a cutoff value of 18.85 , and the diagnostic accuracy rate is $96.7 \%$. Another study found that the average serum level of $25(\mathrm{OH})$ vitamin $D$ in all patients was $11.96 \pm 5.85 \mathrm{ng} / \mathrm{mL}$, with values of $9.79 \pm 4.36 \mathrm{ng} / \mathrm{mL}$ in the case group and $13.61 \pm 6.33 \mathrm{ng} / \mathrm{mL}$ in the control group $(p=0.003)$. Only $15(20.3 \%)$ of the patients had normal vitamin D $25(\mathrm{OH})$ serum levels, while the rest $(79.7 \%)$ had values that were below the normal range. Furthermore, there is no significant variation in vitamin D $25(\mathrm{OH})$ levels between girls and boys, or between groups, according to gender. ${ }^{20}$

The mean level of vitamin $D$ in patients $(18.98 \mathrm{ng} / \mathrm{mL})$ was substantially lower than in controls $(28.07 \mathrm{ng} / \mathrm{mL} ; p=0.001)$, according to Akcan et al. ${ }^{16}$ Severe, moderate, and mild vitamin $D$ deficiencies were reported as $9.5,57.6$, and $14.2 \%$, respectively, in a research conducted in Iran in 2004. ${ }^{21}$ According to Cayir et al., 58 people (69\%) had a vitamin D level of less than $20 \mathrm{ng} / \mathrm{mL}$ (deficient), compared to 32 people (30\%) in the control group. ${ }^{22}$

In 116 children with recurrent AOM, a randomized controlled study was done. The children who received vitamin D supplements were given 1000 IU each day, whereas the others were given a placebo. Rickets is less likely to occur in children who take vitamin $D$ supplements. Furthermore, when vitamin D levels in the blood are greater than $30 \mathrm{ng} / \mathrm{mL}$, the incidence of $A O M$ is reduced dramatically. ${ }^{9}$

In another study, the case group's mean vitamin D level was $26.1 \pm 14.6 \mathrm{ng} / \mathrm{mL}$, with the lowest being $6 \mathrm{ng} / \mathrm{mL}$ and the highest being $67.6 \mathrm{ng} / \mathrm{mL}$.

The mean value in the control group was $29.5 \pm 17.9 \mathrm{ng} / \mathrm{mL}$, with a minimum of $8.1 \mathrm{ng} / \mathrm{mL}$ and a maximum of $139 \mathrm{ng} / \mathrm{mL}$. Vitamin $D$ levels did not differ significantly between the two groups ( $p=0.27)$. Although there was no statistically significant difference in vitamin D levels between the two groups in the study, OM patients had lower vitamin D levels than the control group.

As a result, the author suggests that these individuals' vitamin $D$ levels be measured and that vitamin $D$ deficiency be addressed. ${ }^{15}$

The immune system's regulation by vitamin $D$ is wellestablished.

Monocyte and macrophage chemotaxis and phagocytosis are improved in an environment high in active vitamin D, according to the research.

Vitamin D increases the production of antimicrobial peptides, defense peptides, and cathelicidin peptides by natural killer cells and respiratory epithelial cells. ${ }^{23,24}$

Under the influence of active vitamin D, the levels of calprotectin and protein $\mathrm{S} 100$ rose. These proteins are critical for a healthy natural immune system to function properly. Vitamin D and immunological function have been linked. The immunological response and leukocyte chemotaxis are both hampered when vitamin $D$ levels are low. The infection rate rises as immunity is weakened. ${ }^{25}$

The upper and lower respiratory tract infections, as well as tonsillitis, have been linked to vitamin D insufficiency. ${ }^{26,27}$ Cathelicidin synthesis is reduced in bronchial epithelial cells of patients with frequent respiratory tract infections, according to one study, and inhaled vitamin D can boost cathelicidin synthesis. ${ }^{27}$ Vitamin $D$ can also be used as an adjuvant therapy to treat the number of infections, according to certain research. ${ }^{24,28}$

Although there is a definite link between vitamin D deficiency and $A O M$, there is not enough evidence to reach the same conclusions as with OM.

A study of 16 children with an average age of 3.7 years who were having VT implantation revealed that $50 \%$ of the children had serum vitamin D levels $<20 \mathrm{ng} / \mathrm{mL}$. However, there was no evidence of a link between vitamin D levels and OM in this investigation. ${ }^{29}$

On X-rays, all of the subjects in our research had enlarged adenoids.

Vitamin D insufficiency has been linked to adenoid tonsil hypertrophy in several studies. ${ }^{30,31}$ Most children who had adenoid tonsillectomy were vitamin D deficient, according to one study, and vitamin D levels were inversely associated with tonsil size. ${ }^{32}$ Nunn et al. found that vitamin D prevented mitogen-induced tonsil tissue proliferation in an in vitro research. ${ }^{30}$ Recent adult research has revealed that a considerable majority of OSA patients are also vitamin D deficient. ${ }^{33,34}$

In a Turkish study, children with recurrent tonsillitis and allergic rhinitis had significantly lower levels of 1,25 dihydroxyvitamin D $[1,25(\mathrm{OH}) 2 \mathrm{D}]$ than the control group. ${ }^{35}$

The size of the tonsils and adenoids was found to be inversely linked with serum $25(\mathrm{OH}) \mathrm{D}$ levels in another investigation. ${ }^{36}$ Type B tympanic pressure readings were found in all patients (100\%) in the current investigation; however, only type A was found in the control group. In another study, 70 (87.5\%) of the 80 children in the control group were type $A$ and $10(12.5 \%)$ were $C 1$. Two kids (5\%) were type $C 2$ and 38 (95\%) were type B among the 40 youngsters in the OME group. ${ }^{15}$

Type A tympanogram normal pressure in the middle ear with normal eardrum and ossicles movement has been documented in the literature. A type B tympanogram, on the contrary, may detect fluid in the middle ear. ${ }^{37}$ This is consistent with our findings.

The current study's biggest flaw is that we did not look at the effect of vitamin D on OM and adenoid hypertrophy resolution. As a result, more research on the subject should be conducted in the near future.

\section{CONCLUSION}

Low vitamin D levels are linked to exudative SOM and larger adenoids, according to our findings.

As a result, children with these symptoms should have their serum $25(\mathrm{OH})$ D levels measured.

\section{References}

1. Gombart AF, The vitamin D-antimicrobial peptide pathway and its role in protection against infection. Future Microbiol 2009;4(9): 1151-1165. DOI: 10.2217/fmb.09.87.

2. Esposito $S$, Lelii $M$. Vitamin $D$ and respiratory tract infections in childhood. BMC InfectDis 2015;15(1):487. DOI: 10.1186/s12879-015-1196-1.

3. Erdivanli OC, Coskun ZO, Kazikdas KC, et al. Prevalence of otitis media with effusion among Primary School Children in Eastern Black Sea, in Turkey and the effect of smoking in the development of otitis media with effusion. Indian J Otolaryngol Head Neck Surg 2012;64(1):17-21. DOI: 10.1007/s12070-011-0131-z.

4. Bluestone CD, Stephenson JS, Martin LM. Ten-year review of otitis media pathogens. Pediatr Infect Dis J 1992;11(8 Suppl.):S7-S11. DOI: 10.1097/00006454-199208001-00002. 
5. Poe DS, Abou-Halawa A, Abdel-Razek O. Analysis of the dysfunctional eustachian tube by video endoscopy. Otol Neurotol 2001;22(5):590595. DOI: 10.1097/00129492-200109000-00005.

6. Bhat V, Bhandary SK, Shenoy V. Otitis media with effusion in relation to socio economic status: a community based study. Indian J Otolaryngo Head Neck Surg 2012;64(1):56-58. DOI: 10.1007/s12070-011-0163-4.

7. Ashhurst-Smith C, Hall ST, Burns CJ, et al. In vitro inflammatory responses elicited by isolates of Alloiococcus otitidis obtained from children with otitis media with effusion. Innate Immun 2014;20(3):320-326. DOI: 10.1177/1753425913492181.

8. Cayir A, Turan MI, Ozkan O, et al. Serum vitamin D levels in children with recurrent otitis media. Eur Arch Oto-Rhino-Laryngol 2014;271(4):689-693. DOI: 10.1007/s00405-013-2455-7.

9. Marchisio P, Consonni D, Baggi E, et al. Vitamin D supplementation reduces the risk of acute otitis media in otitis-prone children. Pediatr Infect Dis J 2013;32(10):1055-1060. DOI: 10.1097/INF.0b013e 31829be0b0.

10. Rovers M, Haggard M, Gannon M, et al. Heritability of symptom domains in otitis media: a longitudinal study of 1,373 twin pairs. Am J Epidemiol 2002;155(10):958-964. DOI: 10.1093/aje/155.10.958.

11. Mithal A, Wahl DA, Bonjour J-P, et al. Global vitamin D status and determinants of hypovitaminosis D. Osteoporos Int 2009;20(11): 1807-1820. DOI: 10.1007/s00198-009-0954-6.

12. McGill A, Stewart J, Lithander F, et al. Relationships of low serum vitamin D3 with anthropometry and markers of metabolic syndrome and diabetes in overweight and obesity. Obes Metab 2009;6(4):52-53. DOI: 10.1186/1475-2891-7-4.

13. Timms P, Mannan N, Hitman G, et al. Circulating MMP9, vitamin D and variation in the TIMP-1 response with VDR genotype: mechanisms for inflammatory damage in chronic disorders? QJM 2002;95(12):787-796. DOI: 10.1093/qjmed/95.12.787.

14. Sabetta JR, DePetrillo P, Cipriani RJ, et al. Serum 25-hydroxyvitamin d and the incidence of acute viral respiratory tract infections in healthy adults. PLoS One 2010;5(6):e11088. DOI: 10.1371/journal. pone.0011088.

15. Hosseini S, Khajavi M, Eftekharian A, et al. Vitamin D levels in children with otitis media with effusion: a case-control study. Thrita 2016;5(1). DOI: 10.5812/thrita.31977.

16. Akcan FA, Dündar Y, Akcan HB, et al. Clinical role of vitamin D in prognosis of otitis media with effusion. Int J Pediatr Otorhinolaryngol 2018;105:1-5. DOI: 10.1016/j.ijporl.2017.11.030.

17. Schleicher RL, Sternberg MR, Looker AC, et al. National estimates of serum total 25 -hydroxyvitamin $D$ and metabolite concentrations measured by liquid chromatography-tandem mass spectrometry in the US population during 2007-2010. J Nutr 2016;146(5):1051-1061. DOI: 10.3945/jn.115.227728.

18. Smith $M$, Seasonal, ethnic and gender variations in serum vitamin D3 levels in the local population of Peterborough. Bioscience Horizons 2010;3(2):124-131. DOI: 10.1093/biohorizons/hzq016.

19. Klingberg E, Oleröd G, Konar J, et al. Seasonal variations in serum 25-hydroxy vitamin $D$ levels in a Swedish cohort. Endocrine 2015;49(3):800-808. DOI: 10.1007/s12020-015-0548-3.

20. Asghari A, Bagheri Z, Jalessi $M$, et al. Vitamin D levels in children with adenotonsillar hypertrophy and otitis media with effusion. Iran J Otorhinolaryngol 2017;29(90):29. PMID: 28229060, PMCID: PMC5307302.
21. Hashemipour S, Larijani B, Adibi $H$, et al. Vitamin D deficiency and causative factors in the population of Tehran. BMC Public Health 2004;4(1):38. DOI: 10.1186/1471-2458-4-38.

22. Cayir A, Turan MI, Ozkan O, et al. Vitamin D levels in children diagnosed with acute otitis media. J Pak Med Assoc 2014;64(11):1274-1277. PMID: 25831645.

23. Bikle D. Nonclassic actions of vitamin D. J Clin Endocrinol Metab 2009;94(1):26-34. DOI: 10.1210/jc.2008-1454.

24. Morcos M, Gabr A, Samuel S, et al. Vitamin D administration to tuberculous children and its value. Boll Chim Farm 1998;137(5): 157-164. PMID: 9689902.

25. Szodoray $P$, Nakken $B, G$ aal J, et al. The complex role of vitamin $D$ in autoimmune diseases. Scand J Immunol 2008;68(3):261-269. DOI: 10.1111/j.1365-3083.2008.02127.x.

26. Muhe L, Lulseged S, Mason KE, et al. Case-control study of the role of nutritional rickets in the risk of developing pneumonia in Ethiopian children. Lancet 1997;349(9068):1801-1804. DOI: 10.1016/S01406736(96)12098-5.

27. Yim S, Dhawan P, Ragunath C, et al. Induction of cathelicidin in normal and CF bronchial epithelial cells by 1,25-dihydroxyvitamin D3. J Cyst Fibros 2007;6(6):403-410. DOI: 10.1016/j.jcf.2007.03.003.

28. Cannell J, Vieth R, Umhau J, et al. Epidemic influenza and vitamin D. Epidemiol Infect 2006;134(6):1129-1140. DOI: 10.1017/ S0950268806007175.

29. Linday LA, Shindledecker RD, Dolitsky JN, et al. Plasma 25-hydroxyvitamin D levels in young children undergoing placement of tympanostomy tubes. Ann Otol Rhinol Laryngol 2008;117(10):740744. DOI: $10.1177 / 000348940811701006$.

30. Nunn J, Katz D, Barker S, et al. Regulation of human tonsillar T-cell proliferation by the active metabolite of vitamin D3. Immunology 1986;59(4):479. PMID: 3026959, PMCID: PMC1453330.

31. McCarty DE, Chesson Jr AL, Jain SK, et al. The link between vitamin $D$ metabolism and sleep medicine. Sleep Med Rev 2014;18(4):311-319. DOI: 10.1016/j.smrv.2013.07.001.

32. Reid D, Morton R, Salkeld L, et al. Vitamin D and tonsil diseasepreliminary observations. Int J Pediatr Otorhinolaryngol 2011;75(2):261-264. DOI: 10.1016/j.ijporl.2010.11.012.

33. Piovezan RD, Hirotsu C, Feres MC, et al. Obstructive sleep apnea and objective short sleep duration are independently associated with the risk of serum vitamin D deficiency. PLoS One 2017;12(7). DOI: 10.1371/ journal.pone.0180901.

34. Salepci B, Caglayan B, Nahid P, et al. Vitamin D deficiency in patients referred for evaluation of obstructive sleep apnea. J Clin Sleep Med 2017;13(04):607-612. DOI: 10.5664/jcsm.6554.

35. San T, Muluk NB, Cingi C. 1,25(OH)2D3 and specific IgE levels in children with recurrent tonsillitis, and allergic rhinitis. Int J Pediatr Otorhinolaryngol 2013;77(9):1506-1511. DOI: 10.1016/ j.ijporl.2013.06.019.

36. Shin JH, Kim BG, Kim BY, et al. Is there an association between vitamin $D$ deficiency and adenotonsillar hypertrophy in children with sleep-disordered breathing? BMC Pediatr 2018;18(1):196. DOI: 10.1186/s12887-018-1178-8.

37. Anwar $\mathrm{K}$, Khan $\mathrm{S}$, ur Rehman $\mathrm{H}$, et al. Otitis media with effusion: accuracy of tympanometry in detecting fluid in the middle ears of children at myringotomies. Pak J Med Sci 2016;32(2):466. DOI: 10.12669/pjms.322.9009. 